\title{
Features of the Polar Air Outbreak and the Energy Balance in the Transformed Air-Mass Observed over the Japan Sea
}

\author{
Kozo NINOMIYA \\ Frontier Research Center for Global Change, Japan Agency for Marine-Earth Science and Technology, \\ Yokohama, Japan
}

(Manuscript received 1 September 2004, in final form 23 February 2006)

\begin{abstract}
Features of the polar-air outbreak and the energy balance in the transformed air-mass over the Japan Sea, during a period of strong polar-air outbreak in 1977, are studied by using upper observation data on a research vessel (Keifu-maru) and two coastal stations (Akita and Wajima). The analysis is made over an area of $3.8 \times(100 \mathrm{~km})^{2}$ using vertically dense $(25-\mathrm{hPa}$ interval) data interpolated from data at standard pressure levels and significant levels.

The mixed layer capped by the stable layer is formed in the transformed air-mass. The large apparent heat and moisture sources are evaluated within the mixed layer. The apparent heat and moisture sources decrease abruptly at the top of the mixed layer. The large kinetic energy dissipation due to the sharing stress in the lower layer almost offsets the large generation of the kinetic energy due to the work down by the pressure gradient force.

The present analysis indicates that the use of vertically dense data is important to resolve the multilayer structure of the transformed air-mass, and to obtain accurate vertical distribution of apparent energy sources, in the transformed airmass.

The results of the present analysis are consistent, in general, with numerical simulations on the airmass transformation over the Japan Sea. However, the apparent heat and moisture sources in the lower portion of the boundary layer in this study are considerably small as compared with results of the simulation studies. This discrepancy will be due to the use of data at the land stations on the outflow side of the budget analysis area.
\end{abstract}

\section{Introduction}

The warm sea-current Kuroshio splits into two branches in the East China Sea. While the southern branch flows eastward as the main Kuroshio, the northern branch penetrates into the Japan Sea, as the Tsushima current. During the winter, the Asian continental polar airmass breaks out as the winter monsoon over the warm sea surface of the East China Sea and the Japan Sea. Large sensible and latent

Corresponding author: Kozo Ninomiya, Frontier Research Center for Global Change, Yokohama, 236-0001 Japan.

E-mail: nmiya@jamstec.go.jp

(C) 2006, Meteorological Society of Japan heat energies supplied from the sea surface cause the rapid air-mass transformation.

The air-mass transformation over the East China Sea was extensively studied by many researchers participated in the "Air-Mass Transformation Experiment (AMTEX)". Kondo (1976) estimated heat and moisture supplies from the sea surface, by using the bulk method. Several energy budget analyses (e.g., Ninomiya 1972; Nitta 1976; Murty 1976) evaluated vertical distribution of the apparent heat and moisture sources and also estimated the heat and moisture supplies from the sea surface. Some observational studies (Ninomiya 1976, 1977; Ninomiya and Akiyama 1976; Nitta and So 1980) analyzed the structure of the mixed 
layer, and the heat energy and momentum balances in the mixed layer.

Observational studies on the air-mass transformation over the Japan Sea have the longer history initiated by Manabe (1957). Manabe (1957), Ninomiya (1968), and Kato and Asai (1983) made atmospheric heat and moisture budget analyses over the Japan Sea, using upper observation data at standard (mandatory) pressure-levels, from regular land stations. Hirose et al. (1996) evaluated the long-term mean surface heat fluxes over the Japan Sea by the bulk method, without the study on the energy budget in the atmosphere. The detailed observational studies comparable with AMTEX studies are not performed yet, except for an article by Yamagishi (1980a) on the stratification in the transformed polar airmass.

More detailed studies of the air-mass transformation over a small area of the Japan Sea, comparable with the AMTEX studies, are needed to further the knowledge about the airmass transformation. Detailed observational studies are also needed for the verification of the vertical distribution of the heat and moisture sources obtained in numerical experiments on the polar-air outbreak over the Japan Sea (e.g., Yamagishi 1980b; Yoshizaki et al. 2004; Ninomiya et al. 2006). This is the basic motivation of this article.

The present author keeps some results of observational study over the Japan Sea in winter 1977, which have not been completed, because of the change of his affiliation. A period of quasi-steady strong polar outbreak, between 30 January and 08 February 1977, is selected for the analysis in this report.

\section{Observations and outline of the analysis}

Following AMTEX, a small field experiment "East Japan Sea Observation" was curried out under the cooperation by the Sendai District Meteorological Observatory, Marine Department of Japan Meteorological Agency (JMA) and Meteorological Research Institute (MRI) in the midwinter of 1976 and 1977. The features of the large-scale circulations, and the polar outbreak varied widely during the experiment. Among four sub-periods of the experiment, the sub-period 1977B, between 30 January and 08 February 1977, is characterized by

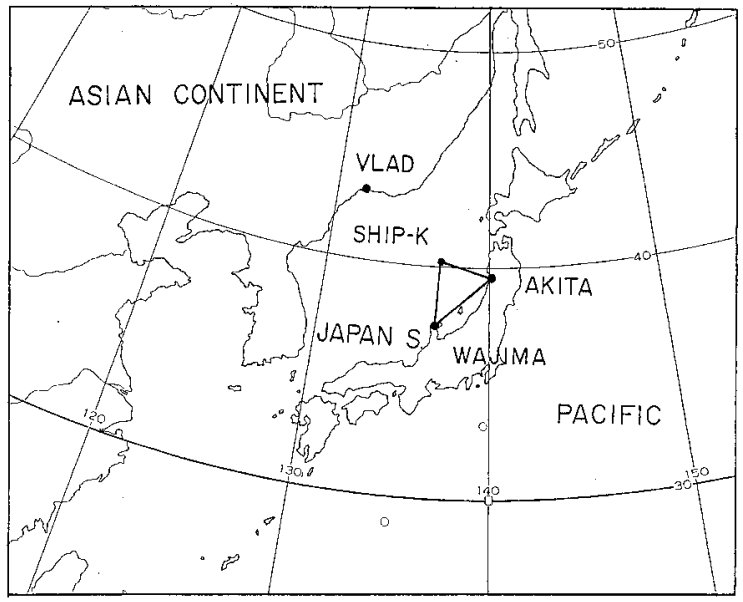

Fig. 1. Locations of upper observation stations (Vladivostok, Akita and Wajima) and the research vessel Keifumaru (Ship-K).

a quasi-steady strong polar outbreak. This subperiod is selected for the analysis in this report.

During the sub-period "1977B", 19 rawin sondes were released from a research vessel Keifu-maru (Ship-K) staying on the central part of the Japan Sea. Figure 1 presents the location of Ship-K. Although, the location of Ship-K fluctuated within a certain distance, this map shows the averaged location in the sub-period. In addition to the data from Ship$\mathrm{K}$, regular rawin sonde observation data from Vladivostok (international station number: 31960), Akita (47-582) and Wajima (47-600), were used for the present study. The triangular area in Fig. 1, surrounding by Ship-K, Akita and Wajima is noted by S-area, hereafter in this report. Heat, moisture, momentum, and kinetic energy budget analyses are made over the S-area. The dimension of the S-area is $3.8 \times(100 \mathrm{~km})^{2}$.

For the present analysis we use the $p^{*}$ coordinate system, which was proposed by Rasmussen (1971), and used by Holland and Rasmusson (1973) for mass, momentum and energy budget computations for "Barbados Oceanographic and Meteorological Experiment (BOMEX)". Ninomiya (1976 and 1977), Ninomiya and Akiyama (1976) used the $p^{*}$ coordinate system for studies of AMTEX. In the $p^{*}$-coordinate system, $p^{*}$ is the position on the vertical axis in terms of pressure differ- 


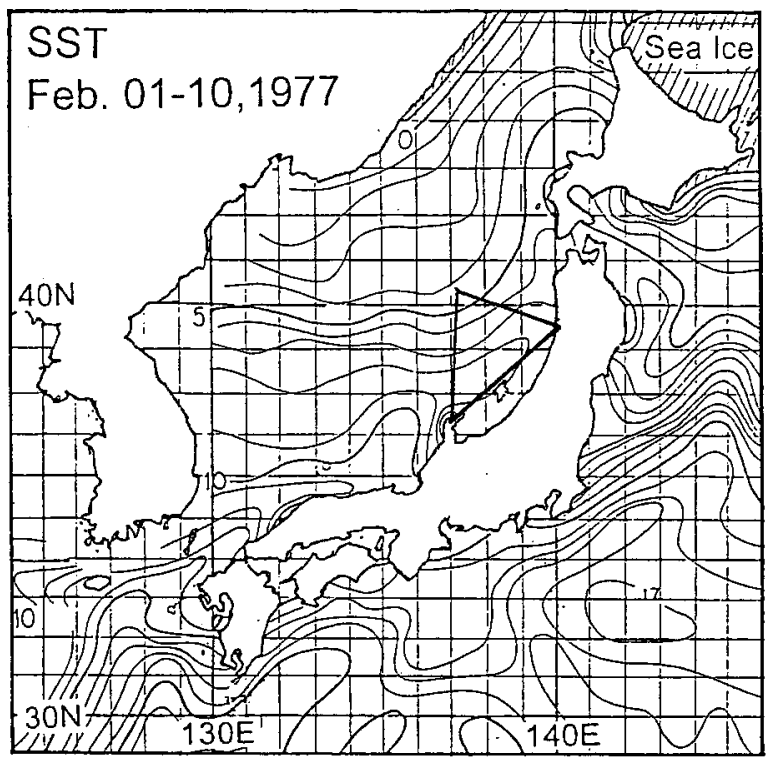

Fig. 2. The sea-surface temperature in 01-10 February 1977.

ential relative to the sea level; that is, $p^{*}=0 \mathrm{hPa}$ at the sea level. The data on the $p^{*}$-coordinate at $25-\mathrm{hPa}$ interval, are first interpolated from the data at standard pressure levels and significant levels.

In addition, the objective analysis data produced by the Numerical Prediction Division of the JMA, are used for the large-scale analysis in Section 3.

\section{Features of polar outbreak during the sub-period 1977B}

Figure 2 presents the sea surface temperature (SST) in 01-10 February 1977. An area of cold water spreads over the northeastern part of the Japan Sea, while the warm Tsushima current extends along the coast of the Japan Islands. The large SST gradient is seen in and around the S-area.

Figure 3A shows the sea-level pressure, and $500-\mathrm{hPa}$ geopotential height averaged for 1977B. The large-scale situation of $1977 \mathrm{~B}$ is characterized by a upper cold-low at $500 \mathrm{hPa}$ over $\sim 47^{\circ} \mathrm{N} / 150^{\circ} \mathrm{E}$, a deep surface Aleutian low over $\sim 49^{\circ} \mathrm{N} / 170^{\circ} \mathrm{E}$, a strong Siberia anticyclone of $\sim 1040 \mathrm{hPa}$, and the strong west-east gradient of the sea level pressure.

Figure 3B shows $850-\mathrm{hPa}$ temperature and wind velocity averaged for 1977B. The large
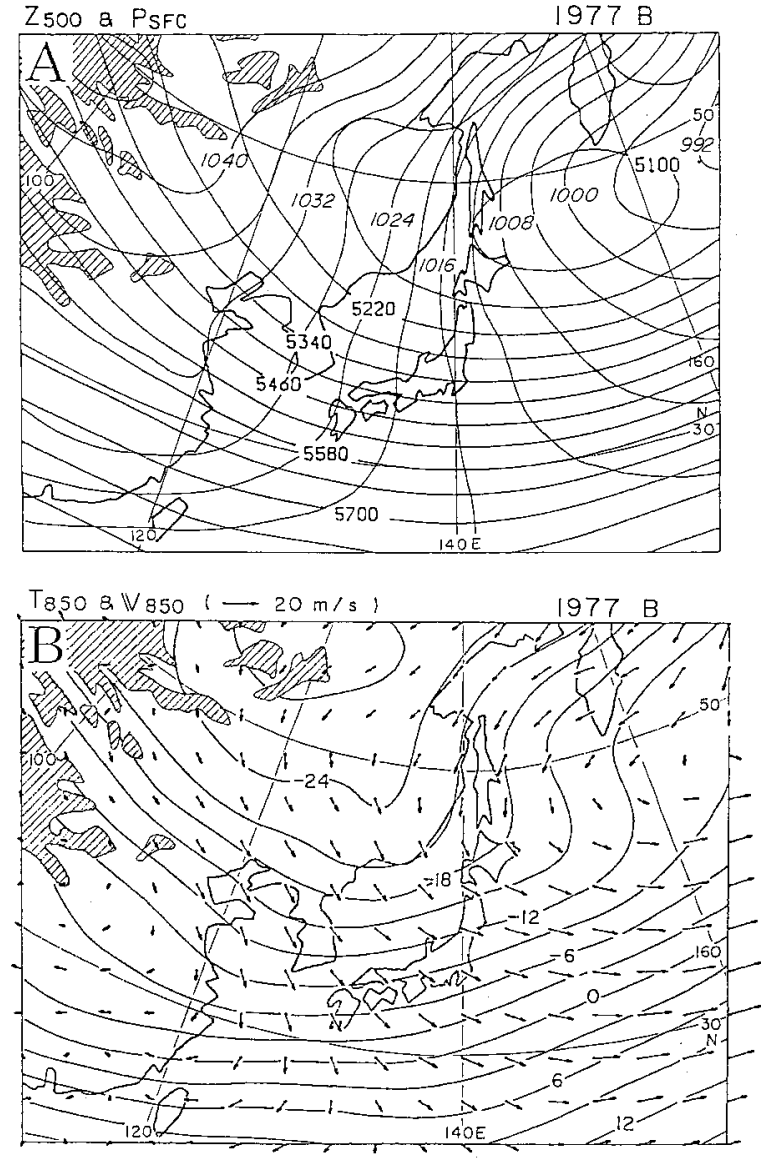

Fig. 3. A: The sea-level pressure (isobars: $4 \mathrm{hPa}$ interval) and 500-hPa geopotential height (height contour; $60 \mathrm{~m}$ interval) averaged for 1977B.

$\mathrm{B}$ : The $850-\mathrm{hPa}$ temperature (isotherms; $3^{\circ} \mathrm{C}$ interval) and wind velocity averaged for 1977B.

$850-\mathrm{hPa}$ temperature gradient of $\sim 15 \mathrm{~K}$ $(1000 \mathrm{~km})^{-1}$ appears over the Japan Sea. While the cyclonic polar-air streams predominate over the Japan Sea and the northwestern Pacific, anticyclonic polar-air streams predominate over the East China Sea. The $850-\mathrm{hPa}$ winds have large velocity component crossing tightly packed isotherms. The horizontal cold advection at $850 \mathrm{hPa}$ over the Japan Sea averaged for $1977 \mathrm{~B}$ reaches to $\sim 0.35 \mathrm{~K} \mathrm{~h}^{-1}$, while that over the Kuroshio region reaches to $\sim 0.40 \mathrm{~K} \mathrm{~h}^{-1}$ (figure is not presented). The horizontal moisture advection at $850 \mathrm{hPa}$ over the Japan Sea, averaged for $1977 \mathrm{~B}$, is $\sim 0.04 \mathrm{~g} \mathrm{~kg}^{-1} \mathrm{~h}^{-1}$, while that over the Kuroshio 


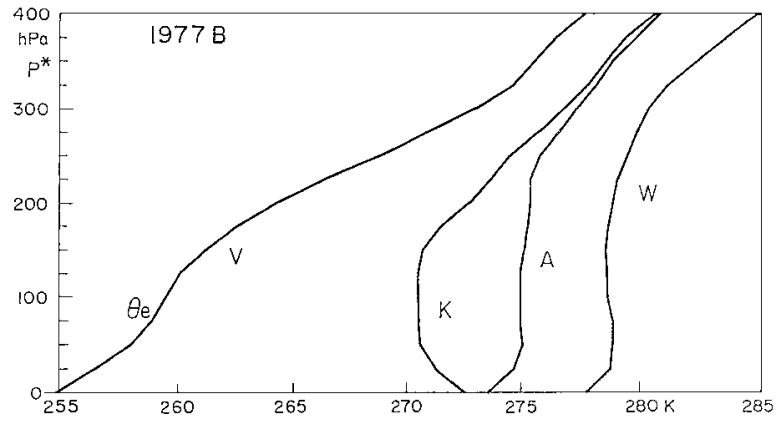

Fig. 4. The vertical profile of equivalent potential temperature $\theta_{e}$ averaged for 1977B at Vladivostok, Ship-K, Akita and Wajima.

region reaches $\sim 0.15 \mathrm{~g} \mathrm{~kg}^{-1} \mathrm{~h}^{-1}$ (figure is not presented).

Figure 4 shows vertical profiles of equivalent potential temperature $\theta_{e}$ at Vladivostok, ShipK, Akita and Wajima averaged for 1977B. Very stable stratification is observed at Vladivostok. This stable stratification changes into the unstable stratification in the process of the airmass transformation over the Japan Sea. The vertical profile of $\theta_{e}$ at Ship-K indicates the convectively unstable layer in $0-50 \mathrm{hPa}$ (in $p^{*}$ ), and the nearly-uniform $\theta_{e}$ layer in 50$150 \mathrm{hPa}$. The deeper uniform layer reaching to $\sim 250 \mathrm{hPa}$ is seen over Akita and Wajima. However, $\theta_{e}$ in $0-25 \mathrm{hPa}$ over these land stations indicate stable stratification.

Figure 5 presents vertical profiles of potential temperature $\theta$, equivalent potential temperature $\theta_{e}$ and saturated equivalent potential temperature $\theta_{e}^{*}$ at Vladivostok, Ship-K and Akita averaged for 1977B. The stratification at Ship- $\mathrm{K}$ is characterized by the super dryadiabatic lapse rate (i.e., the decrease of $\theta$ with increasing height) in the lower portion of the boundary layer (which is noted by the lower boundary layer, hereafter). Observations on Ship-K show the temperature difference of 5$10^{\circ} \mathrm{C}$, between the air temperature at the thermometer level ( $10 \mathrm{~m}$ above the sea surface), and SST during the observation. The nearly dry-adiabatic lapse rate (i.e., uniform $\theta$ ) in 25$75 \mathrm{hPa}\left(p^{*}\right)$ indicates the subcloud layer, while the nearly saturated uniform $\theta_{e}$ layer in 75$150 \mathrm{hPa}\left(p^{*}\right)$ indicates the cloud layer.

At Akita, stable stratification is found in
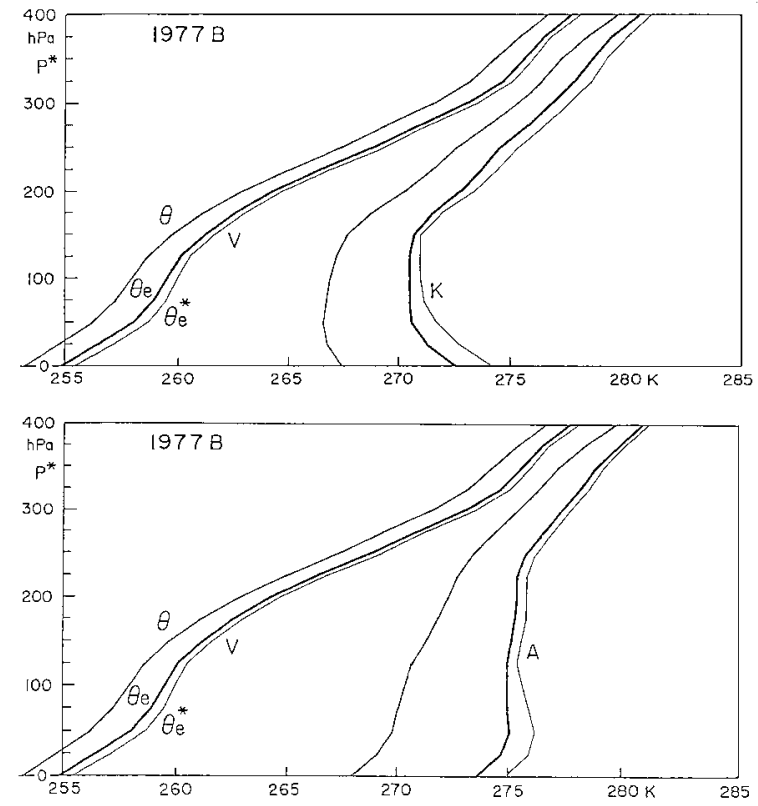

Fig. 5. The vertical profiles of potential temperature $\theta$, equivalent potential temperature $\theta_{e}$ and saturated equivalent potential temperature $\theta_{e}^{*}$ averaged for 1977B at Vladivostok, Ship-K and Akita.

the lower boundary layer $\left(0-25 \mathrm{hPa}: p^{*}\right)$. The nearly-uniform $\theta$ in $50-125 \mathrm{hPa}\left(p^{*}\right)$ corresponds to the averaged subcloud layer, while nearly saturated uniform $\theta_{e}$ layer in 125$250 \mathrm{hPa}\left(p^{*}\right)$ indicates the relatively thick cloud layer over the coastal zone. In the present study, the layer with uniform $\theta_{e}$, which includs the sub-cloud and cloud layers, is defined as the mixed layer.

Echo-top heights of the several significant radar echoes were measured by RHI (rangeheight indicator) observation at Ship-K, Akita and Niigata during 1977B. The averaged echotop height, within the $100-\mathrm{km}$ range of each radar site, is presented in Fig. 6. The echo-top height increases toward downstream of the polar-air streams. This feature is consistent with the distribution of the height of the mixed layer's top, although significant echoes are slightly higher than the mixed layer's top. (The height of $p^{*}$ levels of 100, 200 and $300 \mathrm{hPa}$ are $\sim 0.8, \sim 1.7$ and $\sim 2.7 \mathrm{~km}$, respectively.)

Figure 7 presents hodographs of the time averaged wind velocity at Vladivostok (indi- 
Averaged Echo Top Height

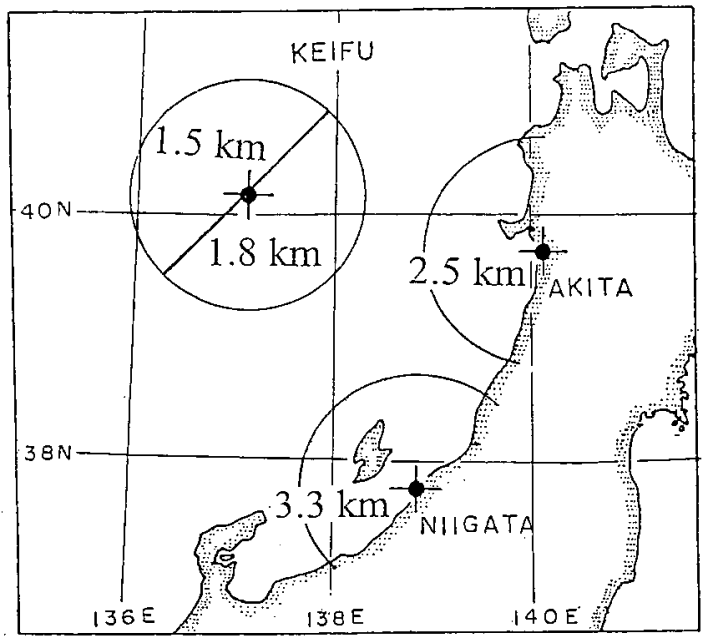

Fig. 6. The echo-top height of significant echo averaged for 1977B.

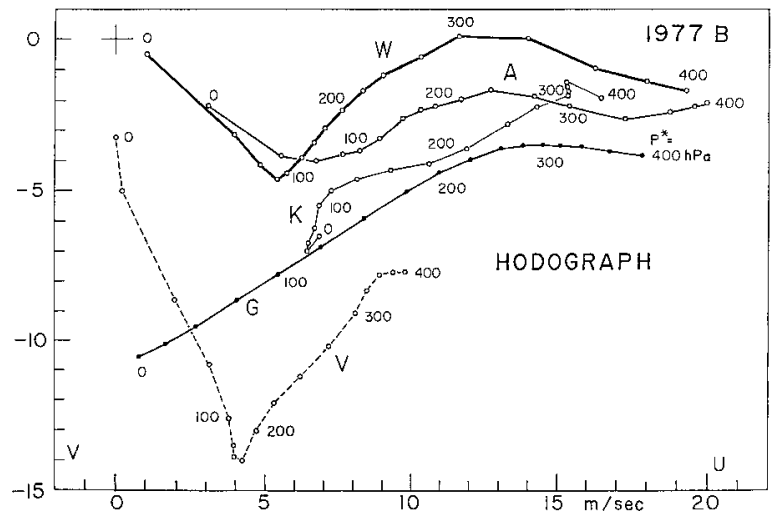

Fig. 7. Wind hodographs of the time averaged wind velocity at Vladivostok (V), Ship-K (K), Akita (A) and Wajima (W). The hodograph of the geostrophic wind $(\mathrm{G})$, which is obtained for the $\mathrm{S}$ area, is also presented in this diagram.

cated by V), Ship-K (K), Akita (A) and Wajima (W). The hodograph of the geostrophic wind, which is obtained for the S-area, is also presented in this diagram $(\mathrm{G})$. The discussion on the large ageostrophic wind component will be made in Section 5. At Ship-K, a layer of the weak vertical wind shear is seen in $0-125 \mathrm{hPa}$ $\left(p^{*}\right)$. The significant vertical mixing of the momentum occurs only over the Japan Sea. At Wajima and Akita, the weak wind shear is seen in $50-125 \mathrm{hPa}\left(p^{*}\right)$.
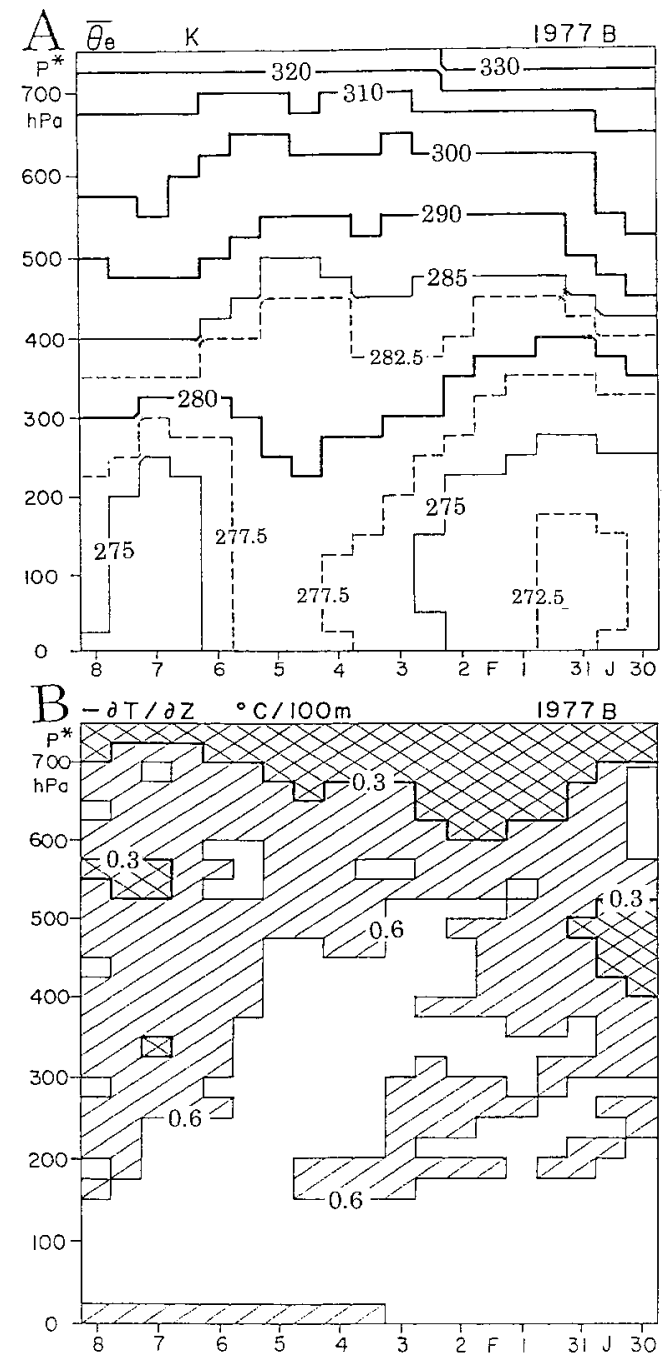

Fig. 8. A: Height-time section of equivalent potential temperature $\theta_{e}$ in the S-area during 1977B.

B: Height-time section of temperature lapse rate $\Gamma=-(\partial T / \partial z)$ in the $\mathrm{S}$-area during 1977B.

Although Wajima and Akita stations are apart only a few kilometers from the coast line, the temperature lapse rate, and the vertical wind shear in the lower boundary layer indicate strong influence of the land surface. If we would have rawin sonde observations, a few kilometers offshore of these stations, the observations might indicate features similar to the observations at Ship-K.

Figures $8 \mathrm{~A}$ and $8 \mathrm{~B}$ show the height-time sections of equivalent potential temperature $\theta_{e}$, 

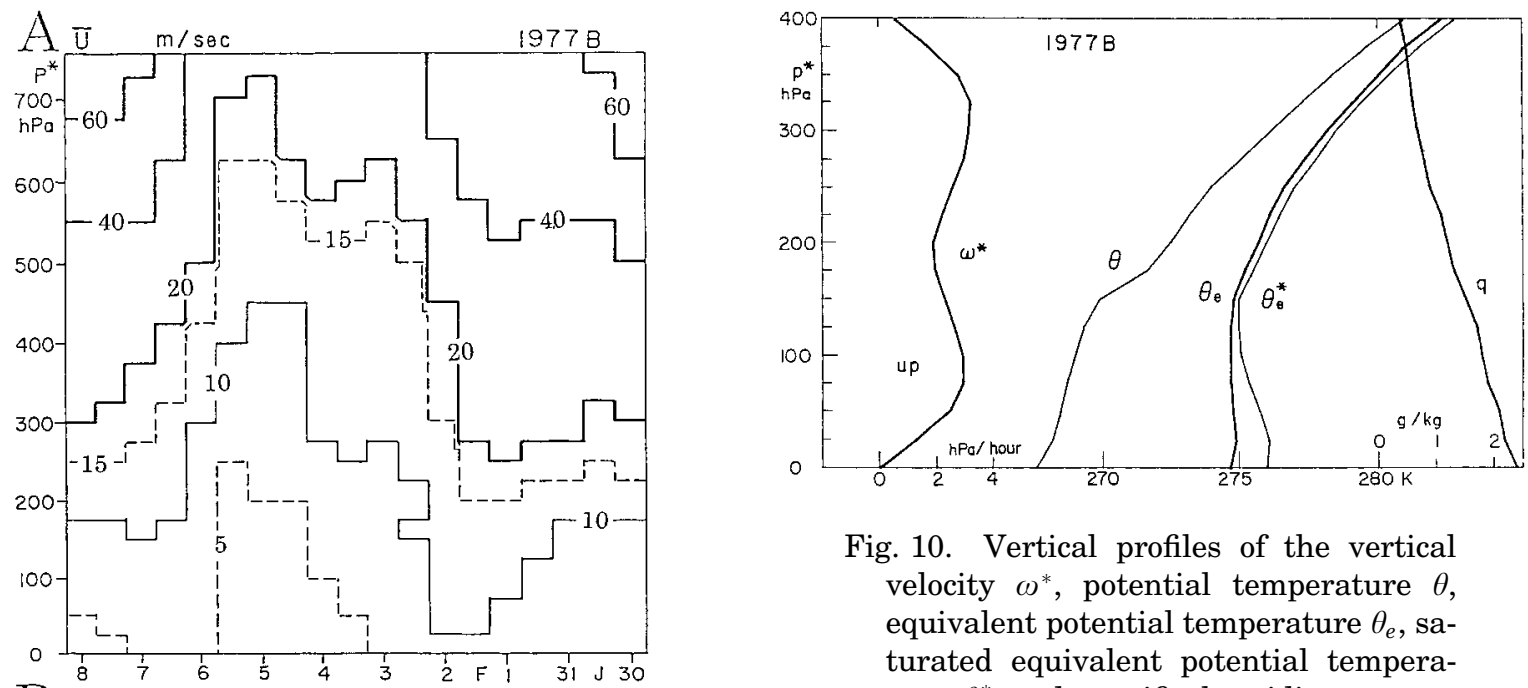

Fig. 10. Vertical profiles of the vertical velocity $\omega^{*}$, potential temperature $\theta$, equivalent potential temperature $\theta_{e}$, saturated equivalent potential temperature $\theta_{e}^{*}$ and specific humidity $q$ averaged over the S-area and for 1977B.

Figure 10 presents vertical profiles of potential temperature $\theta$, equivalent potential temperature $\theta_{e}$, saturated equivalent potential temperature $\theta_{e}^{*}$ and specific humidity $q$, averaged over the S-area and for 1977B. The quasiuniform $\theta_{e}$ layer, which is decided from the area averaged profile of $\theta_{e}$, is seen in $0-150 \mathrm{hPa}$ $\left(p^{*}\right)$. The very small difference between $\theta_{e}^{*}$ and $\theta_{e}$ in $100-150 \mathrm{hPa}\left(p^{*}\right)$ indicates the cloud layer. The specific humidity in the layer above the mixed layer's top is very small, due to the low temperature. by

The vertical velocity, $\omega^{*}=d p^{*} / d t$, is obtained

Fig. 9. Height-time section of zonal (A) and meridional (B) components of wind velocity in the S-area during 1977B.

and temperature lapse rate $\Gamma=-(\partial T / \partial z)$ in the S-area during 1977B. The vertical extension of the mixed layer, which is characterized by nearly-uniform $\theta_{e}$, is limited by the stable layer, in which the temperature lapse late is less than $\sim 0.6 \mathrm{~K}(100 \mathrm{~m})^{-1}$. During 1977B, the mixed layer capped by the stable layer is sustained quasi-stationary. Figure 9 presents height-time sections of zonal and meridional components of wind velocity in the S-area during 1977B. While synoptic-scale variations of winds appeared in the free atmosphere above the stable layer, quasi-stationary northwesterly winds prevailed in the mixed layer.

$$
\omega^{*}\left(p^{*}\right)=-\int_{0}^{p^{*}} \nabla V d p^{*}
$$

The artificial correction of $\omega^{*}$, such as proposed by O'Brien (1970) is not applied for the present analysis. The vertical profile of $\omega^{*}$, averaged for the S-area and 1977B, is presented in Fig. 10. The vertical velocity $\omega^{*}$ of $\sim 3 \mathrm{hPa} \mathrm{h}^{-1}$ (ascending motion), appears within the mixed layer.

\section{Heat and moisture budgets in the transformed air-mass}

The heat and moisture budget calculations are made over the S-area, using equations for the $p^{*}$-coordinate, proposed by Rasmusson (1971). The apparent heat source, and apparent moisture source are evaluated by 


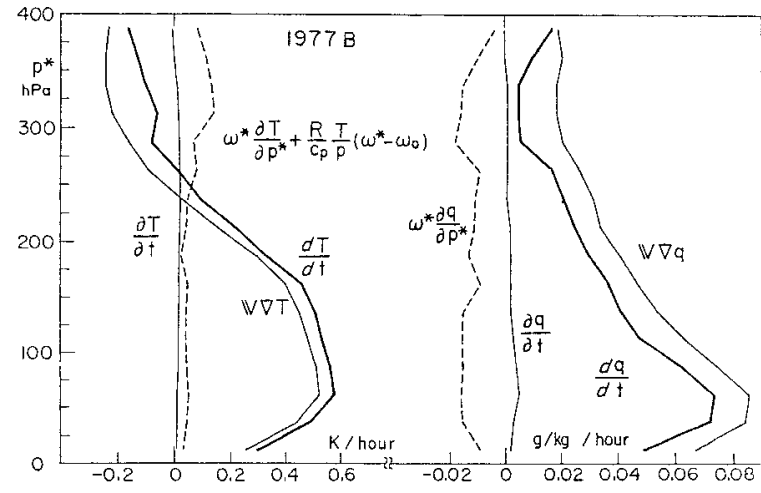

Fig. 11. Results of the heat energy and water vapor budget calculations over the S-area for 1977B.

$$
\frac{d T}{d t}=\frac{\partial T}{\partial t}+V \cdot \nabla T+\omega^{*} \frac{\partial T}{\partial p^{*}}+\frac{R}{c_{p}} \frac{T}{p}\left(\omega^{*}-\omega_{0}\right),
$$

and

$$
\frac{d q}{d t}=\frac{\partial q}{\partial t}+V \cdot \nabla q+\omega^{*} \frac{\partial q}{\partial p^{*}} .
$$

Here, $T, q, R$ and $c_{p}$ are temperature, specific humidity, gas constant for air, and specific heat of air at constant pressure, respectively.

The vertical velocity at the surface $\omega_{0}$ is obtained by

$$
\omega_{0}=(\partial p / \partial t)_{s f c}+V_{s f c} \cdot \nabla p_{s f c} .
$$

Figure 11 shows the vertical profiles of each term in Eq. (2) and Eq. (3), averaged for 1977B. In both Eq. (2) and Eq. (3), the horizontal advection terms are predominant in the mixed layer.

The thermal and moisture advections are small in the lower boundary layer. It was already noted in Section 3 that the vertical distribution of temperature, specific humidity and wind velocity in the lower boundary layer at Akita and Wajima, indicate strong influence of the land. Therefore, the horizontal thermal and moisture advections in the lower boundary layer in the S-area, might be considerably underestimated as compared with the expected situations over the sea area. This problem will be discussed again in Section 7 .

The vertical distribution of the apparent sensible heat source $(d T / d t)$, apparent latent heat source $\left(L / c_{p}\right)(d q / d t)$, and apparent total heat

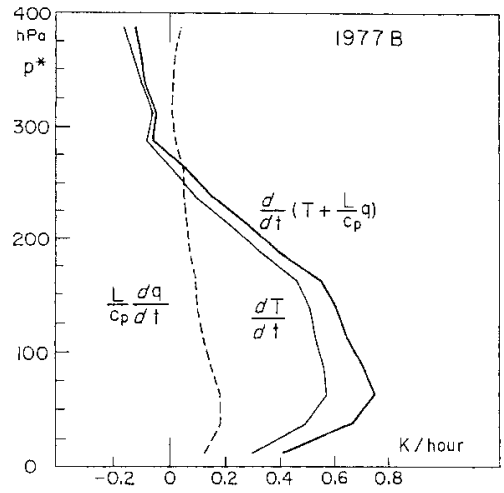

Fig. 12. Vertical profiles of $(d T / d t),\left(L / c_{p}\right)$ $\cdot(d q / d t)$, and $\left[(d T / d t)+\left(L / c_{p}\right)(d q / d t)\right]$ averaged for 1977B.

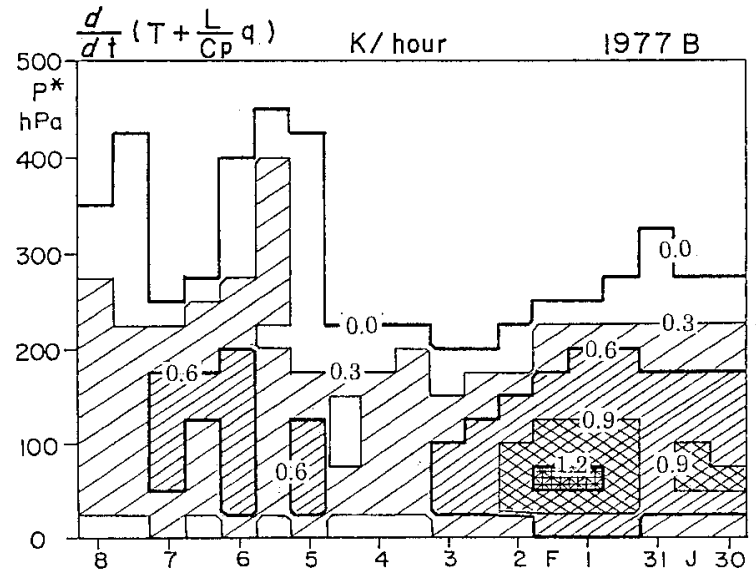

Fig. 13. Height-time section of the apparent total heat source, $[(d T / d t)+$ $\left.\left(L / c_{p}\right)(d q / d t)\right]$ in the S-area during 1977B.

source $\left[(d T / d t)+\left(L / c_{p}\right)(d q / d t)\right]$, averaged for 1977B are presented in Fig. 12. Figure 13 presents the height-time section of the apparent total heat source in the S-area during 1977B. In Fig. 12 and Fig. 13, the significant apparent total heat source appears only within the mixed layer caped by the stable layer. The apparent total heat source decreases at the base of the stable layer. Significant total heat source does not appear in the layer above the base of the stable layer.

For comparison with bulk estimations, the surface energy fluxes are estimated from the results of the energy budget analysis. The total heat energy flux at the sea surface is evaluated 
by

$$
\begin{aligned}
& F_{s}=\left(\frac{c_{p}}{g}\right) \int_{0}^{p_{t o p}^{*}}\left[\left(\frac{d T}{d t}\right)+\left(\frac{L}{c_{p}}\right)\left(\frac{d q}{d t}\right)\right. \\
& \left.-\left(\frac{d T}{d t}\right)_{R}\right] d p^{*}
\end{aligned}
$$

Here $p_{t o p}^{*}$ is the $p^{*}$ at the top of the mixed layer, which is decided from the vertical distribution of area averaged $\theta_{e} .(d T / d t)_{R}$, and $g$ expresses the heating rate due to the radiative process and acceleration of gravity, respectively. The total radiative heating of $-25 \mathrm{~W} \mathrm{~m}^{-2}$ is evaluated in 1000-700 $\mathrm{hPa}$ layer, from the vertical distribution of $(d T / d t)_{R}$ obtained by Manabe (1957). Kato and Asai (1983) estimated total radiative heating of $-20 \mathrm{~W} \mathrm{~m}^{-2}$, in $1000-$ $600 \mathrm{hPa}$ layer. The total heat energy flux $\left(F_{s}=H+L E\right)$ of $380 \mathrm{~W} \mathrm{~m}^{-2}$ is evaluated over the S-area, when the total radiative heating of $-20 \mathrm{~W} \mathrm{~m}^{-2}$ is assumed in Eq. (5), where $H$, $L E, L$ and $E$ are sensible, and latent heat fluxes at the surface, latent heat of vaporization for water and evaporation, respectively.

In order to evaluate $H$ and $L E$ separately, the estimation of the condensation (precipitation) is needed. The precipitation observed over the coastal zone is $3-4 \mathrm{~mm} \mathrm{~d}^{-1}$, while Ship-K did not record measurable precipitation. If the area averaged precipitation in the S-area is assumed to be $2 \mathrm{~mm} \mathrm{~d}^{-1}, H$ and $L E$ is estimated to be 230 and $150 \mathrm{~W} \mathrm{~m}^{-2}$, respectively, which give the evaporation of $5 \mathrm{~mm} \mathrm{~d}^{-1}$, and Bowen's ratio of 1.5. If the area of averaged precipitation is assumed to be $3 \mathrm{~mm} \mathrm{~d}^{-1}, H$ and $L E$ is estimated to be 200 and $180 \mathrm{~W} \mathrm{~m}^{-2}$, respectively, which give the evaporation of $6 \mathrm{~mm} \mathrm{~d}^{-1}$, and Bowen's ratio of 1.1 .

\section{Momentum and kinetic energy budgets in the transformed air-mass}

Figure 14 presents vertical profiles of the averaged meridional and zonal wind velocity, and those of the geostrophic wind velocity over the S-area. The geostrophic wind components are evaluated by

$$
u_{g}=-\left(\frac{g}{f}\right)\left[\left(\frac{\partial Z}{\partial y}\right)+\left(\frac{\alpha}{g}\right)\left(\frac{\partial p_{0}}{\partial y}\right)\right]
$$

and

$$
v_{g}=\left(\frac{g}{f}\right)\left[\left(\frac{\partial Z}{\partial x}\right)+\left(\frac{\alpha}{g}\right)\left(\frac{\partial p_{0}}{\partial x}\right)\right] .
$$

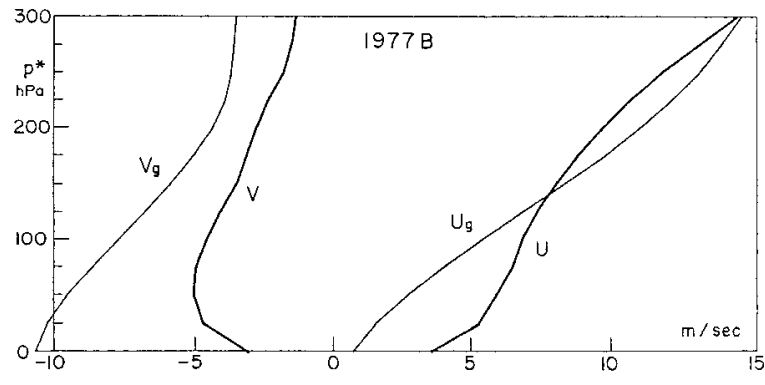

Fig. 14. Vertical profiles of the meridional and zonal wind velocity and those of the geostrophic wind velocity over the Sarea and for 1977B.

Here $Z, f, \alpha$, and $p_{0}$ indicate height of the pressure level $p^{*}$, Coriolis parameter, specific volume of air and sea-level pressure, respectively. While the geostrophic wind components increase almost linearly with the increasing height, the observed wind components indicate relatively weak vertical shear in $25-125 \mathrm{hPa}$ $\left(p^{*}\right)$. The large ageostrophic wind velocity appears in the lower layer.

The momentum equations are

$$
\begin{aligned}
\left(\frac{d u}{d t}\right)= & f v+\left(\frac{u v \tan \varphi}{a}\right) \\
& -g\left[\left(\frac{\partial Z}{\partial x}\right)+\left(\frac{\alpha}{g}\right)\left(\frac{\partial p_{0}}{\partial x}\right)\right]+F_{x} \\
= & f v+\left(\frac{u v \tan \varphi}{a}\right)-f v_{g}+F_{x},
\end{aligned}
$$

and

$$
\begin{aligned}
\left(\frac{d v}{d t}\right)= & -f u-\left(\frac{u^{2} \tan \varphi}{a}\right) \\
& -g\left[\left(\frac{\partial Z}{\partial y}\right)+\left(\frac{\alpha}{g}\right)\left(\frac{\partial p_{0}}{\partial y}\right)\right]+F_{y} \\
= & -f u-\left(\frac{u^{2} \tan \varphi}{a}\right)+f u_{g}+F_{y},
\end{aligned}
$$

Where, $(d u / d t)$ and $(d v / d t)$ are the substantial change of $u$ - and $v$-momentums, $\varphi$ and $a$ are the latitude and the radius of the earth, respectively.

The $x$ - and $y$-components of the frictional force $F_{x}$ and $F_{y}$ are evaluated as the residual terms in Eq. (9) and Eq. (10) and expressed by

$$
F_{x}=g\left(\partial \tau_{x} / \partial p^{*}\right)
$$




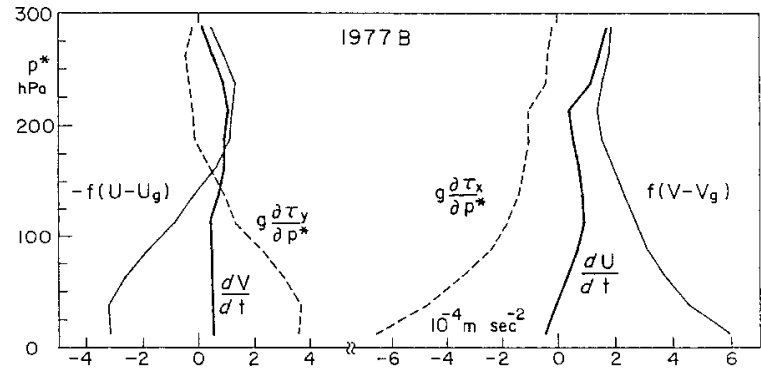

Fig. 15. Results of momentum budget calculations over the S-area for 1977B.

and

$$
F_{y}=g\left(\partial \tau_{y} / \partial p^{*}\right) .
$$

Here $\tau_{x}$ and $\tau_{y}$ are $x$ - and $y$-components of stress.

The budget equation of the kinetic energy, $K=(1 / 2)\left(u^{2}+v^{2}\right)$, is

$$
(d K / d t)=-\left(g V \cdot \nabla Z+\alpha V \cdot \nabla p_{0}\right)+g V \cdot\left(\partial \tau / \partial p^{*}\right) .
$$

Here $(d K / d t)$ is the substantial change of the kinetic energy. The first term in the right hand of Eq. (12) is the generation of the kinetic energy due to the work down by the pressure gradient force. The kinetic energy loss, due to the frictional force, which is expressed by the second term in Eq. (12), is evaluated as the residual of the budget equation.

Figure 15 shows results of momentum budget calculations over the S-area. In the momentum budget equations, Eq. (8) and Eq. (9), the second terms in the right hand are negligibly small. Although the substantial increase of $u$-momentum occurs in the lower layer, due to the work down by the ageostrophic winds, the effect of the ageostrophic wind is almost offset by the friction. The substantial change of $v$ momentum is relatively small throughout the mixed layer, and the effect of ageostrophic wind is balanced by the frictional loss of the momentum. The ageostrophic wind and the frictional loss are large in the lower layer, and vanish in the stable layer covering the cloud layer.

Figure 16 shows results of the kinetic energy budget over the S-area. In this diagram, $\mathrm{G}$ indicates the generation of the kinetic energy, and F.L indicates the frictional loss of the kinetic

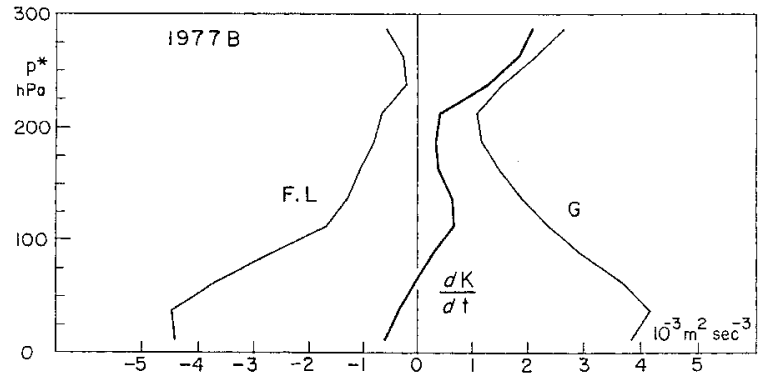

Fig. 16. Results of the kinetic energy budget over the S-area for 1977B. G indicates the generation of the kinetic energy. F.L indicates the frictional loss of the kinetic energy estimated as the residual of the budget equation.

energy, estimated as the residual of Eq. (12). Both the generation and the frictional loss indicate large magnitude in the lower layer. The large kinetic energy dissipation, due to the sharing stress of $-4 \times 10^{-3} \mathrm{~m}^{2} \mathrm{~s}^{-3}$, almost offsets the large generation of the kinetic energy due to the work down by the pressure gradient force. Both terms indicate minimum values around the top of the cloud layer.

We note that the generation of the kinetic energy is relatively small in the lower boundary layer. This will be due to the use of data from the land stations in the outflow side of the area for budget computations.

\section{Comparison with previous observational studies over the Japan Sea}

Yamagishi (1980b) estimated surface energy fluxes by bulk method using the data at Ship$\mathrm{K}$, for a comparison with the results of his numerical experiments. He obtained sensible and latent heat fluxes of 200 and $150 \mathrm{~W} \mathrm{~m}^{-2}$, and Bowen's ratio of 1.3 in January 31, 1977. He also obtained sensible and latent heat fluxes of 150 and $120 \mathrm{~W} \mathrm{~m}^{-2}$, and Bowen's ratio of 1.2 in February 02, 1977. He noted that the sensible and latent heat fluxes, simulated by his regional model, are significantly larger than these estimated from the bulk method.

He also obtained the time averaged values of sensible and latent heat fluxes of 130 and $120 \mathrm{~W} \mathrm{~m}^{-2}$, and Bowen's ratio of 1.1 by the bulk method for the period between January 30 and February 08, 1977. Meanwhile, Hirose 
et al. (1996) estimated the climatological values of sensible and latent heat fluxes of 140 and $200 \mathrm{~W} \mathrm{~m}^{-2}$ and Bowen's ratio of 0.7 in the area in the vicinity of Ship-K of this study. The difference between the estimation by Yamagishi (1980b) and that by Hirose et al. (1996), will be due to the differences in synoptic-scale features of the polar-air outbreak. Hirose et al. (1996) did not present the variance or standard deviation of fluxes and Bowen's ratio. Considerable differences among the reports indicate that the estimations by the bulk method themselves contain significant uncertainty.

The results of this budget analysis over the S-area, shows the sharp decrease of the apparent heat and moisture sources at the top of the mixed layer. Therefore, the vertical integration of the apparent heat and moisture sources from the sea-level to the top of the mixed layer will give the reasonable estimation of the fluxes.

Considering the discussion mentioned above, the results of heat and moisture budget analyses over the Japan Sea by Manabe (1957) and Ninomiya (1968) are reexamined. For a period of strong polar-air outbreak in 1955, Manabe (1957) obtained sensible heat flux of $510 \mathrm{~W} \mathrm{~m}^{-2}$, latent heat flux of $220 \mathrm{~W} \mathrm{~m}^{-2}$, and Bowen's ratio of 2.3 by the budget analysis, while he estimated Bowen's ratio of 1.0 by the bulk method. Ninomiya (1968) evaluated sensible heat flux of $470 \mathrm{~W} \mathrm{~m}^{-2}$, latent heat flux of $200 \mathrm{~W} \mathrm{~m}^{-2}$, and Bowen's ratio of 2.3 during a period of strong polar-air outbreak in 1963 by the budget analysis, while he estimated sensible heat flux of $360 \mathrm{~W} \mathrm{~m}^{-2}$, latent heat flux of $310 \mathrm{~W} \mathrm{~m}^{-2}$ and Bowen's ratio of 1.2 by the bulk method.

In their analyses, the sensible and latent heat fluxes were estimated by the vertical integration of the apparent sensible and latent heat sources from the sea-level to $500 \mathrm{hPa}$. While the air-mass transformation is limited in the lower troposphere below $3 \mathrm{~km}$, considerable apparent heat source was estimated in 700$500 \mathrm{hPa}$ layer by their budget analyses. The inclusion of the unrealistic apparent heat source in the layer above the inversion in the vertical integration, might yield overestimation of the sensible heat flux. Using the vertical profiles of the apparent sensible heat source, and the apparent moisture source given in Manabe (1957), the vertical integration of the apparent sensible, and latent heat sources, from the sealevel to $700 \mathrm{hPa}$ is calculated to estimate the surface fluxes. This estimation gives the sensible heat flux of $400 \mathrm{~W} \mathrm{~m}^{-2}$, latent heat flux of $190 \mathrm{~W} \mathrm{~m}^{-2}$, and Bowen's ratio of 2.1. From the vertical profiles of the apparent sensible heat source, and the apparent moisture source given in Ninomiya (1968), the vertical integration of the apparent sensible and latent heat sources, from the sea-level to $700 \mathrm{hPa}$ is calculated. This estimation gives the sensible heat flux of $370 \mathrm{~W} \mathrm{~m}^{-2}$, latent heat flux of $210 \mathrm{~W} \mathrm{~m}^{-2}$, and Bowen's ratio of 1.8 .

In some cases, unrealistic apparent heat sink was calculated in the layer above the top of the mixed layer (e.g., Area-B in AMTEX'74; Fig. 23 of Ninomiya and Akiyama 1976). In such cases, the total heat flux would be underestimated if it was estimated by the vertical integration of the apparent heat source from the sea-level to $500 \mathrm{hPa}$.

The aforementioned discussions suggest that the vertical integration of the apparent heat and moisture sources, from the sea-level to the top of the mixed layer, which is identified in the proper domain, is necessary for the reasonable fluxes estimation.

\section{Comparison with the result of numerical simulation over the Japan Sea}

Yamagishi (1980b) made a numerical experiment of the air-mass transformation over the Japan Sea, using a 64-km grid regional model. The model has 13 levels (5 levels in the layer below $900 \mathrm{hPa}$ ), with top at $100 \mathrm{hPa}$. The physical processes in his model are surface exchange of heat, moisture and momentum, based on the similarity theory, vertical turbulent transfer of heat, moisture and momentum, based on the turbulent closure model of level-2, and, the moist convective adjustment. While the observed sea surface temperature is kept unchanged during the integration, the land surface temperature is predicted by the heat balance condition including the radiative processes. The radiative processes in the atmosphere are not included in the model. He performed simulation from the observed initial condition for two cases in the period 1977B. Heat, moisture fluxes and Bowen's ratio of $360 \mathrm{~W} \mathrm{~m}^{-2}, 270 \mathrm{~W} \mathrm{~m}^{-2}$, and $\sim 1.3$ are obtained 
for January 31, 1977, nearby the S-area. Heat, moisture fluxes and Bowen's ratio of $\sim 280 \mathrm{~W} \mathrm{~m}^{-2}, \sim 230 \mathrm{~W} \mathrm{~m}^{-2}$, and $\sim 1.2$ are obtained for February 02, 1977. Heat source $(d \theta / d t)$ of $\sim 0.8 \mathrm{~K} \mathrm{~h}^{-1}$, and moisture source $(d q / d t)$ of $\sim 0.12 \mathrm{~g} \mathrm{~kg}^{-1} \mathrm{~h}^{-1}$, are simulated in the mixed layer for January 31, 1977. However, the sharp decrease of the heat source at the top of the mixed layer is not well simulated, presumably due to the insufficient vertical resolution in the layer above $900 \mathrm{hPa}$. The warming and the moistening rates, due to the vertical convergence of the vertical eddy transfer, are large in the lowest layer [i.e., $(d \theta / d t)$ of $\sim 3 \mathrm{~K} \mathrm{~h}^{-1}$, and $(d q / d t)$ of $\sim 0.4 \mathrm{~g} \mathrm{~kg}^{-1} \mathrm{~h}^{-1}$. These large warming and moistening rates compensate the cooling and drying, due to the moist convective adjustment. As the result, the features of the mixed layer, and the heat and moisture balances in the mixed layer, are reasonably simulated in his model. While the large heat and moisture sources appear in the lowest layers in his simulation, the apparent heat and moisture sources estimated by the present analysis are small in the lower boundary layer.

In his model, the momentum change due to the vertical eddy transfer nearly compensates the momentum change due to the ageostrophic winds in the transformed air-mass. The kinetic energy balance in his model (Fig. 10 in Yamagishi 1980b), indicates large kinetic energy dissipation due to the sharing stress of $-4 \times 10^{-3} \mathrm{~m}^{2} \mathrm{~s}^{-3}$, which almost offsets the large value of the generation term in the lower layer. His results are consistent with this budget analysis.

Yoshizaki et al. (2004), made a short-range prediction experiment using a nonhydrostatic regional model (5-km grid with 38-levels), for the polar-air outbreak over the Japan Sea. Their results for 14 January 2001 are consistent with the present analysis in regard to the multi-layer structure, and the heat energy balance in the transformed air-mass, except the apparent heat and moisture sources in the lower boundary layer.

Ninomiya et al. (2006), studied the polar-air outbreak over East Asia in a climate simulation, using an atmospheric general circulation model (T106L52; a primitive equation spectrum model, which has $52 \sigma$-levels and triangular spectral truncation at wave-number 106).
Features of the mixed layer and the heat and moisture balances in the mixed layer over the Japan Sea in their simulations are consistent with results of the present analysis as to the multi-layer structure, and the heat energy balance in the transformed air-mass, except the lower boundary layer.

While the large heat and moisture sources appear in the surface boundary layer over the sea in those simulations, the apparent heat and moisture sources in the lower boundary layer over the S-area estimated in this analysis are significantly small. This discrepancy will be mainly due to the use of data at the land stations (Akita and Wajima) on the outflow-side of the S-area. If we would apply the temperature lapse rate, relative humidity, and vertical wind shear in $0-50 \mathrm{hPa}\left(p^{*}\right)$, observed over Ship-K, to the data over Akita and Wajima, the larger temperature and moisture advections would be estimated. By using this assumed data in the lower boundary layer, we estimate $(d \theta / d t)$ of $\sim 0.5 \mathrm{~K} \mathrm{~h}^{-1}$, and $(d q / d t)$ of $\sim 0.08 \mathrm{~g} \mathrm{~kg}^{-1} \mathrm{~h}^{-1}$ in the lower boundary layer.

\section{Comparison with the air-mass transformation over the East China Sea}

The features of the air-mass transformation over the S-area and those over the AMTEX area are compared. Although these sea areas are located nearby the Japan Islands, the largescale features over these areas during the polarair outbreak are significantly different from each other. Basically, the polar air-streams over the Japan Sea exhibit the cyclonic northwesterly circulations, around the extratropical cyclone that develops over the western North Pacific, while the polar air-streams over the East China Sea indicate anticyclonic northeasterly flows around the anticyclone that dominates over the Asian continent (Fig. 3B). The ascending motion occurs during the polar outbreak over the S-area (Fig. 10), while the subsiding motion predominates in the lower troposphere over the AMTEX area during the polar outbreak (e.g., Ninomiya 1977).

The difference between SST in these areas is also an important factor. It brings the difference in the features of the air-mass transformation over these areas. The SST in the S-area of this study is $4-8^{\circ} \mathrm{C}$, while that over the AM- 
Table 1. Features of air-mass transformation during the polar-air outbreak over the AMTEX area and the S-area.

\begin{tabular}{|l|c|c|}
\hline & AMTEX area & S-area \\
\hline Polar-air streams & Anticyclonic northeasterly & Cyclonic northwesterly \\
\hline SST & $18^{\circ} \mathrm{C}$ & $6^{\circ} \mathrm{C}$ \\
\hline Surface air temp. & $10^{\circ} \mathrm{C}$ & $-2^{\circ} \mathrm{C}$ \\
\hline Surface $q$ & $5 \mathrm{~g} \mathrm{~kg}^{-1}$ & $2 \mathrm{~g} \mathrm{~kg}^{-1}$ \\
\hline$\omega^{*}$ & $-7 \mathrm{hPa} \mathrm{h}^{-1}($ decent$)$ & $3 \mathrm{hPa} \mathrm{h}^{-1}$ (ascent) \\
\hline Mixed layer's top & $2000 \mathrm{~m}$ & $2000 \mathrm{~m}$ \\
\hline$d T / d t$ & $0.6 \mathrm{~K} \mathrm{~h}^{-1}$ & $0.6 \mathrm{~K} \mathrm{~h}^{-1}$ \\
\hline$d q / d t$ & $0.3 \mathrm{~g} \mathrm{~kg}^{-1} \mathrm{~h}^{-1}$ & $0.07 \mathrm{~g} \mathrm{~kg}^{-1} \mathrm{~h}^{-1}$ \\
\hline Total heat flux & $550 \mathrm{~W} \mathrm{~m}^{-2}$ & $370 \mathrm{~W} \mathrm{~m}^{-2}$ \\
\hline Frictional force & $6 \times 10^{-4} \mathrm{~m} \mathrm{~s}^{-2}$ & $6 \times 10^{-4} \mathrm{~m} \mathrm{~s}^{-2}$ \\
\hline Frictional loss of $\mathrm{K}$ & $6 \times 10^{-3} \mathrm{~m}^{2} \mathrm{~s}^{-3}$ & $5 \times 10^{-3} \mathrm{~m}^{2} \mathrm{~s}^{-3}$ \\
\hline
\end{tabular}

TEX area is $18-22^{\circ} \mathrm{C}$. Consequently, the Bowen's ratio obtained over the AMTEX area is smaller than that over the Japan Sea.

Table 1 summarizes the characteristics of the air-mass transformation over the AMTEX area and the S-area. The most important difference is found in the apparent moisture source $(d q / d t)$. Owing to the lower air-temperature, the specific humidity, the horizontal moisture gradient and the horizontal moisture advection, are small in the S-area, as compared with those in the AMTEX area. The heat and moisture budget calculations indicate a smaller value of evaporation from the sea surface in the S-area as compared with that over the AMTEX area, although the amount of the apparent heat source $(d T / d t)$ over the S-area is almost same to that over the AMTEX area. The small value of $(d q / d t)$ in the S-area accounts for a small value of the total apparent heat source, as well as the total heat energy flux at the sea surface.

Another important difference is seen in features of the stable layer covering the mixed layer. Especially in the phase of strong subsidence over the AMTEX area, the very stable layer or even the inversion layer, is frequently formed (Ninomiya 1977). Such predominant stable layer, or inversion layer, is not often seen over the S-area.

\section{Concluding remarks}

This article describes features of the polar air-mass transformed over the Japan Sea, during the sub-period 1977B of the "East Japan Sea Observation", which is characterized by quasi-steady strong polar-air outbreak. The vertically dense $(25-\mathrm{hPa}$ interval) data are used for the analysis.

The multi-layer structure of the transformed air-mass, including the unstable lower boundary layer, a mixed layer that is characterized by vertically uniform equivalent potential temperature, capped by the stable layer, is formed in association with the air-mass transformation over the Japan Sea. The mixed layer includes the sub-cloud layer and cloud layer. The height of the mixed layer's top is $\sim 1500 \mathrm{~m}$ over the central part of the Japan Sea, and increases toward the south. The top reaches to $\sim 2500 \mathrm{~m}$ over the coastal area of Japan. The unstable boundary layer appears only over the sea. The sensible heat energy, moisture, momentum and kinetic energy budget in the transformed air-mass are also analyzed. The results of this analysis are qualitatively consistent with the previous bulk estimation and simulation studies, although some quantitative discrepancies are pointed out. 
The heat energy budget analyses over the whole domain of the Japan Sea, using the data on the standard pressure levels (Manabe 1957; Ninomiya 1968) overestimate the sensible heat energy supply from the sea surface, as compared with the estimation by the bulk method. The inclusion of the unrealistic apparent heat source in the layer above the inversion in the vertical integration, might yield overestimation of the sensible heat flux in their analyses. Such large overestimation of the sensible heat supply is avoided by the vertical integration of the apparent heat source from the surface to the top of the mixed layer in the present analysis.

The use of the vertically dense data for the budget calculation is necessary to obtain the accurate vertical distribution of the apparent heat and moisture sources comparable with results of the numerical simulation.

The results of a numerical experiment on the air-mass transformation over the Japan Sea (Yamagishi 1980b; Yoshizaki et al. 2004; Ninomiya et al. 2006) are consistent with results of this analysis for the most part, except smaller apparent heat and moisture sources in the lower boundary layer obtained in the present analysis. This will be due to the use of data from the land stations in the outflow side of the S-area. In future, the energy budget analysis, using data from the network of research vessels alone, is desired for the conclusive evaluation.

Some discrepancies among the budget analysis, bulk estimation and the numerical simulations suggest some unreliability still remain in observation data, budget calculations, bulk estimations and physical processes in numerical models. We need more synthetic comparisons to obtain definite conclusion.

The features of the air-mass transformation over the Japan Sea are compared with those over the East China Sea (AMTEX area). The cyclonic northwesterly polar air-streams predominate over the Japan Sea, while the anticyclonic northeasterly polar air-streams predominate over the East China Sea. The ascending motion occurs over the S-area during the polar outbreak, while the subsiding motion predominates over the AMTEX area.

The SST in the S-area of the present study is $4-8^{\circ} \mathrm{C}$, while that over the AMTEX area is $18-$ $22^{\circ} \mathrm{C}$. Due to the lower air-temperature, the specific humidity, the horizontal moisture gradient, and the horizontal moisture advection are small in the S-area, as compared with those in the AMTEX area. The apparent moisture source $(d q / d t)$ in the S-area is small as compared with that in the AMTEX area, while the apparent heat source $(d T / d t)$ over the $\mathrm{S}$-area is almost the same to that over the AMTEX area. A significant difference is also seen in features of the stable layer covering the mixed layer. The very stable layer or even the inversion layer is frequently formed over the AMTEX area in association with the strong subsidence. Such predominant stable layer is not frequently seen over the S-area. Meanwhile, significant differences in the momentum and kinetic energy budget, are not seen between the S-area and the AMTEX area.

\section{Acknowledgements}

The present author expresses his sincere gratitude to members of the "East Japan Sea Observation", especially to Mr. K. Tamura and Mr. M. Kurosawa of the Sendai District Meteorological Observatory (at that time), and Mr. Y. Abe of the Akita Local Meteorological Observatory (at that time), for valuable contribution to this project. The present author also thanks two anonymous reviewers for their valuable comments and advice.

\section{References}

Hirose, N., C.-H. Kim, and J.-H. Yoon, 1996: Heat budget in the Japan Sea. J. Oceanography, 52, $553-574$.

Holland, J.Z. and E.M. Rasmusson, 1973: Measurements of the atmospheric mass, energy, and momentum budgets over a 500-kilometer square of tropical ocean. Mon. Wea. Rev., 101, 44-55.

Kato, K. and T. Asai, 1983: Seasonal variations of heat budgets in both the atmosphere and the sea in the Japan Sea area. J. Meteor. Soc. Japan, 61, 222-238.

Kondo, J., 1976: Heat balance of the East China Sea during the Air-Mass transformation Experiment. J. Meteor. Soc. Japan, 54, 382-398.

Manabe, S., 1957: On the modification of air-mass over Japan Sea when the outburst of cold air predominates. J. Meteor. Soc. Japan, 35, 311326.

Murty, K., 1976: Heat and moisture budgets over AMTEX area during AMTEX 75. J. Meteor. Soc. Japan, 54, 370-381. 
Ninomiya, K., 1968: Heat and water budget over the Japan Sea and the Japan Islands in winter season. J. Meteor. Soc. Japan, 46, 343-372.

-, 1972: Heat and water-vapor budget over the East China Sea in the winter season. J. Meteor. Soc. Japan, 50, 1-17. , 1976: Wind profile and kinetic energy budget in the mixed layer of polar air-mass transformed over Kuroshio region. J. Meteor. Soc. Japan, 54, 361-369.

_ 1977: Heat energy budget of the polar airmass transformed over Kuroshio region under the situation of strong subsidence. J. Meteor. Soc. Japan, 55, 431-441.

and T. Akiyama, 1976: Structure and heat energy budget of mixed layer capped by inversion layer during the period of polar outbreak over Kuroshio region. J. Meteor. Soc. Japan, 54, 160-174.

, T. Nishimura, T. Enomoto, T. Suzuki, and S. Matsumura, 2006: Polar-air outbreak and airmass transformation over the east coast of Asia as simulated by an AGCM. J. Meteor. Soc. Japan, 84, 47-68.

Nitta, T., 1976: Large-scale heat and moisture budget during the Air-Mass Transformation Experiment. J. Meteor. Soc. Japan, 54, 1-14.
- and S.S. So, 1980: Structure and heat, moisture and momentum budgets of a convective mixing layer during AMTEX '75. J. Meteor. Soc. Japan, 58, 378-393.

O'Brien, J., 1970: Alternative solutions to the classical vertical velocity problem. J. Appl. Meteor., 9, 197-203.

Rasmusson, E.M., 1971: Mass, momentum and energy budgets equations for BOMAP computations. NOAA Technical Memorandum, ERL BOMAP-3, 32 pp.

Yamagishi, Y., 1980a: Some characteristics of the stable layer over the Japan Sea during winter season (in Japanese). Tenki, 27, 322-329.

- 1980b: Simulation of the air-mass transformation process using a numerical model with the detailed boundary layer parameterization. J. Meteor. Soc. Japan, 58, 357-377.

Yoshizaki, M., T. Kato, H. Eito, S. Hayashi, and W.-K. Tao, 2004: An overview of the field experiment "Winter Mesoscale Convective Systems over the Japan Sea in 2001", and comparisons of the cold-air outbreak case (14 January) between analysis and a non-hydrostatic cloudresolving model. J. Meteor. Soc. Japan, 82, 1365-1387. 